\title{
Primary Open Angle Glaucoma: Epidemiological, Clinical and Therapeutic Aspects of 63 Cases at National Hospital Center in Mauritania
}

\author{
Mohamed Jiddou Sidi Baba ${ }^{1,2}$, Ahmedou Moulaye Idriss ${ }^{1 *}$, Tfeil Yahya ${ }^{1}$, \\ Ahmed Taleb Batty2, Sidi Sidi Cheikh ${ }^{1,2}$ \\ ${ }^{1}$ Faculty of Medicine of Nouakchott, Nouakchott, Mauritania \\ ${ }^{2}$ Ophthalmology Department of National Hospital Center of Nouakchott, Nouakchott, Mauritania \\ Email: *carcinologie@yahoo.fr
}

How to cite this paper: Baba, M.J.S., Idriss, A.M., Yahya, T., Batty, A.T. and Cheikh, S.S. (2020) Primary Open Angle Glaucoma: Epidemiological, Clinical and Therapeutic Aspects of 63 Cases at National Hospital Center in Mauritania. Open Journal of Ophthalmology, 10, 229-240. https://doi.org/10.4236/ojoph.2020.103025

Received: July 5, 2020

Accepted: August 23, 2020

Published: August 26, 2020

Copyright $\odot 2020$ by author(s) and Scientific Research Publishing Inc. This work is licensed under the Creative Commons Attribution International License (CC BY 4.0).

http://creativecommons.org/licenses/by/4.0/

(c) $\underset{\mathrm{By}}{\mathrm{i}}$ Open Access

\begin{abstract}
Introduction: Primary open angle glaucoma (POAG) is an anterior optic neuropathy of chronic and progressive course, characterized by perimeter alteration and excavation of the specific optic disc. This neuropathy is usually accompanied by ocular hypertonia. The iridocorneal angle remains open in gonioscopy. POAG is the primary cause of irreversible blindness in adults around the world, posing a real public health and quality of life problem as well as an economic problem. The progressive and irreversible loss of vision makes POAG a disease that can lead to blindness. The main objective of our study is to describe the epidemiological, clinical and therapeutic aspects of primary open angle glaucoma in the ophthalmology department of the National Hospital Center of Nouakchott. Materials and Methods: It was a prospective descriptive study of 6 months (March $1^{\text {st }} 2017$ to August $30^{\text {th }}$ 2017), on patients with a POAG with the presence of at least one of the three signs (intraocular pressure $>21 \mathrm{mmHg}$, papillary cup/disc vertical excavation $\geq 0.5$ and a field altered apart from all other causes). All glaucoma patients seen during the study period benefited from a complete eye examination. The studied variables were the family history of glaucoma, age, intra ocular pressure (IOP) and pachymeter. Results: The mean age was 58.7 years. About 2/3 of the patients had a lower pachymeter to normal ( $63 \%$ of cases), a genetically thinner cornea results in an underestimation of the IOP measurement. The male was the most represented with a sex ratio $\mathrm{M} / \mathrm{F}$ (1.42), the main characteristic factors were family history of glaucoma (39.7\%), artery hypertension, diabetic and headache. The success rate of surgery was $69.8 \%$, while $11 \%$ of our patients had refused any kind of treatment, no complications were noted, Conclusion: POAG is a multifactorial condition which can lead to blindness if not early diagnosed or if treatment is poorly conducted, hence the impor-
\end{abstract}


tance of prevention by screening and informing the population about this pathology.

\section{Keywords}

Glaucoma, Intraocular Pressure, Mauritania

\section{Introduction}

Primary open angle glaucoma (POAG) is an anterior optic neuropathy of chronic and progressive course, characterized by perimeter alteration and excavation of the specific optic disc [1]. This neuropathy is usually accompanied by ocular hypertension. The iridocorneal angle remains open in gonioscopy.

POAG is the primary cause of irreversible blindness in adults around the world, posing a real public health and quality of life problem as well as an economic problem. The progressive and irreversible loss of vision makes POAG a disease that can lead to blindness [1] [2]. The definition of this disease, in the epidemiological sense, is not perfectly clear. However, most of the studies have been carried out using the classic symptomatic triad: ocular hypertension, modification of the optical disc morphology (papillary excavation) and impairment of the visual field. The impairment of the visual structure and of the vision itself is retained, in the final analysis, as a criterion of the disease [3]. According to recent estimations of the prevalence of the disease, primary open-angle glaucoma is the second leading cause of blindness worldwide after cataracts (46\%) affecting around 66 million people [3]. The POAG is the most frequent of the glaucomas since it represents according to the regions and diagnostic criteria $50 \%$ to $70 \%$ of the total of the glaucomas and would be at the origin of 6.4 million cases of blindness in the world [4]. The prevalence of POAG is variable depending on the origin. It is relatively low in a European-type population (1\% of people over 40 years), and is higher and earlier in blacks, which is more serious and difficult to treat [2]. In sub-Saharan Africa, the prevalence varies from one country to another. It is $7 \%$ in Togo [5] and $4.2 \%$ in Mali, among people aged over 30 years 1998 [6]. Due to the asymptomatic nature of the disease in initial phase and slowly progressive course, many cases are not detected. There are very few data on the incidence of blindness from glaucoma. Data from the Canadian Institute of the Blind suggest that the incidence in Quebec is around 140 cases per year, corresponding to prevalence with 1260 cases [7].

The main objective of this work was to describe the epidemiological, clinical and therapeutic aspects of primary open angle glaucoma in the ophthalmology department in the National Hospital Center of Nouakchott.

\section{Patients and Method}

It is a prospective, monocentric observational descriptive study for analytical 
purposes carried out over a period of six months (March $1^{\text {st }} 2017$ to August $30^{\text {th }}$ 2017), in the ophthalmology department of the National Center Hospital of Nouakchott. We included all patients with open-angle glaucoma followed in the outpatient service of our department. Patients with closed angle glaucoma, as well as patients lost to follow-up during check-ups were excluded. After taking a full history and ophthalmological examination including, visual acuity, analysis of the anterior segment, measurement of the ocular pressure with automatic tonometer of Topcon, all patients are listed. Gonioscopy was carried out in all patients by using the Goldmann glass with three mirrors. The evaluation of the head of the optic nerve was carried out by slit lamp examination using a Volksuperfield lens and was confirmed by retinography. The central corneal thickness was measured using an ultrasonic pachymeter which allowed us to correct the value of the measured ocular pressure. The Octopusa visual field was performed each time the visual acuity allowed. (the clinical features of primary open-angle glaucoma are an open iridocorneal angle and cupping of the optic-nerve head (or optic disk), with corresponding loss of visual field. Elevated intra-ocular pressure is not part of the clinical definition because primary open-angle glaucoma can occur when intraocular pressure is normal). All patients received first-line medical treatment. Selective laser trabeculoplasty and open trabeculectomy were indicated as secondary treatment for POAG in 18 cases.

To assess compliance with medical treatment, the following elements were considered:

- Knowledge of the disease.

- Regularity of taking treatment.

- Voluntary interruption of treatment.

- Forgotten of the treatments in the seven days preceding the consultation.

- The regularity of the presentation at the meetings.

Data were collected using exploitation sheet and have been analyzed on IBM SPSS 20

\section{Results}

From 488 patients only 63 (12.9\%) patients were seen in specialized glaucoma consultation with Mean age of 58.7 years (19 - 77), the group age most affected were 50 - 59 years with 22 patients (34.9\%) with sex ratio M/F was 1.42 . The distribution of socio-demographic state and presentation of the patients are summarized in both Table 1 and Table 2 .

In our study $61.9 \%$ of our patients had a visual acuity greater than $6 / 10$ and $7.9 \%$ had a negative light perception (NLP). Associated cataract was found in $22.2 \%$ of our patients. Photomotor reflex was negative in $8 \%$.

The average of the ocular pressure in our patients was $27.34 \mathrm{mmHg} \pm 5.86$ (13 $\mathrm{mmHg}-50 \mathrm{mmHg}$ ). In $47 \%$ of our patients an average value of $1.6 \mathrm{mmHg}$ was added to the measured IOP. All patients had a 360-degree open angle. 
Table 1. The socio-demographic and clinical characteristics.

\begin{tabular}{rrcc}
\hline & Item & Number & Percentage (\%) \\
\hline \multirow{3}{*}{ sex } & mace & 37 & 58.7 \\
& female & 26 & 41.3 \\
Family history & white & 28 & 44.4 \\
& black & 35 & 55.6 \\
& with & 25 & 39.7 \\
& HTA & 38 & 60.3 \\
& Diabetic & 15 & 23.80 \\
HTA + diabetic & 8 & 12.69 \\
MIOPIA & 4 & 6.35 \\
trauma ocular & 14 & 22.23 \\
surgery ocular & 5 & 7.94 \\
without risk factor & 5 & 7.94 \\
\hline
\end{tabular}

Table 2. Distribution by reason of consultation.

\begin{tabular}{ccc}
\hline Item & Number & Percentage (\%) \\
\hline Reduced Visual Acuity (RVA) & 34 & 54 \\
RVA + Head ache & 15 & 24 \\
RVA + Head ache + Vision Trouble & 05 & 08 \\
Head ache & 04 & 06 \\
Vision Trouble & 03 & 05 \\
Head ache + Vision Trouble & 02 & 03 \\
Total & 63 & 100 \\
\hline
\end{tabular}

The eyes with a cup/disc ratio between 0.3 and 0.7 were $59.5 \%$ and $40 \%$ had a cup/disc between $0.8-1$. Nasal rejection of the vessels was noted in $85 \%$ of the patients. No peripapillary hemorrhage was observed.

The chief plaints were the reduced visual acuity followed by the head ache (Table 2).

As monotherapy, beta blockers (BB) are the most prescribed (55.5\% of patients), while in dual therapy the combination of a beta blocker with a prostaglandin analogue is the most used (7.9\% of patients).

In triple therapy, the combination of a beta-blocker with a carbonic anhydrase inhibitor and prostaglandin analogue is the most prescribed (12.7\%) (Table 3).

Trabeculectomy was indicated in 18 patients and 3 of them refused the operative procedure.

Nine patients were benefited from isolated filter surgery, while 5 Patients were undergone combination surgery. 
The average eye pressure before trabeculectomy was $25.7 \mathrm{mmHg}$.

All the patients had undergone an ophthalmological examination with eye pressure measurement on Day $1,1^{\text {st }}$ month, $2^{\text {nd }}$ months, $3^{\text {rd }}$ months and $6^{\text {th }}$ months respectively.

We considered the surgery to be successful if the Ocular Pressure fall down below $20 \mathrm{mmHg}$ without any hypotonizing treatment during the first three months.

Five patients had kept an Ocular pressure at $22 \mathrm{mmHg}$ and were on monotherapy.

The success rate of surgery was $69.8 \%$ in our series.

No complications were noted, but $11 \%$ of our patients had refused any kind of treatment.

Thirty-one $(50 \%)$ of our patient have some knowledge about disease, while $31 \%$ used the treatment regularly, whereas $8 \%$ have stopped their treatment spontaneously (Table 4).

\section{Discussion}

The World Health Organization estimated that 4.5 million people were affected by POAG blindness in 2008 worldwide; which represents more than $12 \%$ of the world blindness rate [8]. POAG is the most common glaucoma in the West and in Africa. Depending on the region, it represents $50 \%$ to $70 \%$ of all glaucoma [9].

In white populations aged 40 and over, prevalence between $1.1 \%$ and $2.1 \%$ is

Table 3. Therapeutic classes used in our patients.

\begin{tabular}{ccc}
\hline Item & Number & Percentage (\%) \\
\hline Beta-Blockers (BB) & 35 & 55.5 \\
Prostaglandins (PG) & 02 & 03.2 \\
Carbonic Anhydrase Inhibitors (CAI) & 01 & 01.6 \\
BB + PG & 05 & 07.9 \\
BB + CAI & 04 & 06.3 \\
BB + Adrenergic (ADR) & 03 & 04.8 \\
BB + CAI + ADR & 02 & 03.2 \\
BB + CAI + PG & 08 & 12.7 \\
BB + CAI + PG + ADR & 03 & 04.8
\end{tabular}

Table 4. Distribution of patients according to different methods of measuring compliance.

\begin{tabular}{ccc}
\hline Item & Number & Percentage \% \\
\hline Knowledge of the disease & 31 & 50 \\
Regularity of treatment & 20 & 31 \\
Refusal of surgical or medical treatment & 7 & 8 \\
Voluntary interruption of treatment & 5 & 11 \\
\hline
\end{tabular}


reported from the results of various studies carried out around the world. The prevalence in black subjects is 3 to 4 times higher than in the whites, with at least 4 times more blindness [10]. In the United States, approximately $15 \%$ of blind subjects are due to POAG.

In Morocco, a national survey was carried out in 1992 by the epidemiological assessment team of blindness and concluded that the gross point prevalence of blindness in Morocco is $0.76 \%$, that of the decrease in bilateral vision of $2.27 \%$, and that of unilateral vision loss $2.8 \%$ [11]. Glaucoma represented $14.3 \%$ of the etiologies of this blindness constituting the second cause after cataract. Lower incidence has recently been demonstrated in the Visual Impairment Project, carried out in Melbourne, Australia (1.1\% for suspect and certain POAGs), and in the Rotterdam Study (5-year risk of $1.8 \%$ for suspicious and some POAGs). The two studies mentioned above, the incidence increases significantly with age [12]. Frequency of disease increases with age, passing beyond 5\% in subjects over 65 years old. In the Baltimore Eye survey, the prevalence of glaucoma is 3.5 times higher for subjects between 70 and 80 years old compared to those between 40 and 50 years [13]. The age of onset of glaucoma is, however, variable depending on the series. Mean age in our study is 58.7 years \pm 11.6 which is comparable with the finding of the A. Chakiband all (10), Fifties and sixties age groups were the most represented, Distribution of patients by sex showed a male predominance with $58.7 \%$ of men and $41.3 \%$ women which is lower than that of A. Chakib [11] who found a predominance of the male sex at $73.6 \%$.

In Wales, Beaver Dam and Melbourne studies no statistical association with sex was found [14].

In our study, the black race was the most affected with $55.6 \%$, which is comparable with the finding of Baltimore study (12), Statistically, POAG is more common in black subjects. In the Baltimore Eye Survey [13], black subjects had 3 to 4 times more glaucoma than white subjects.

However, it is believed that the abundance of pigments in melanodermal subjects are responsible for the obstruction of the trabecular meshwork, the place of excretion of the aqueous humor which is blocked and so causes ocular hypertension responsible for POAG.

Family history of glaucoma in this study was present in $39.7 \%$ while Z. Fadou [15] found $37.1 \%$. Family history is also a risk factor for glaucoma.

The Baltimore study indicates that the relative risk of having a POAG increases approximately 3.7 times when individuals have parents who are themselves glaucomatous. In the Rotterdam study, relatives of a patient with glaucoma have a greatly increased risk of developing glaucoma (Relative Risk: 9.2) [15].

In our study, confirmed diabetic was found in $12.7 \%$ of patients which is higher than that founded by Carlos E. Rivera and all [16], which was (4.8\%), on the other hand both are lower than that founded by Z. Fadou [15], where 28.6\% of patients were diabetic. Several studies report an increased prevalence of POAG in diabetic populations. 
In the Rotterdam Study and the Blue Mountains Eye Study, diabetic patients have a risk of developing glaucoma approximately 2 to 3 times higher than non-diabetic patients; the Beaver Dam Study finds the same trend, but without reaching the same statistical significance. In contrast, the Baltimore Eye Study and the Visual Impairment Project show no link between diabetes and glaucoma.

In our study, $23.8 \%$ of patients were followed for hypertension which is lower than that founded in the series of O. laplace et al. (2006) [17] 30\% of cases and that finded by Z. Fadou [15] 33.6\%.

An association between blood pressure and ocular perfusion pressure have been reported. In a 9-year longitudinal study, increases in IOP in black subjects were correlated with hypertension and diabetes. The role of hypertension as a risk factor for the appearance of glaucoma appears less clear, some studies show an important link, between glaucoma and high IOP, approximately multiplied by $2[15]$.

In our study, myopia was founded in $23.6 \%$ of cases that is higher than that founded by O. Laplace et al. (2006) series [17], 13.1\%.

An association has been reported between POAG and myopia. Because the patients with a refractive problem consult more often, and therefore have a higher probability than emmetropes of being detected earlier. The association of a POAG and myopia can both complicate diagnosis and treatment.

In this study $88.9 \%$ of the patients had consulted for an RVA; which joins the series of Z. Fadou [15], 90.7\% in 2012. The study shows $61.9 \%$ of our patients had corrected visual acuity greater than $6 / 10$ in the right eye and $57.1 \%$ in the left eye, while Z. Fadouand al. [15] found $52.9 \%$ of the right eyes and $52.1 \%$ of the left eyes had more than 6/10. However, in 2012 Sounouvou [18] found in his study $47.3 \%$ of the right eyes and $43.8 \%$ of the left eyes had more than $6 / 10$. There is no correlation between visual acuity and the severity of glaucoma.

The pictorial expression which marks the memory illustrates it well "the blind man who reads $10 / 10$, it is chronic glaucoma at the pre-terminal stage!" Because the central vision responsible for the acuity is affected last while the peripheral vision has been affected for a long time.

The assessment of a deficit in the afferent pupillary reflex can detect an asymmetric lesion of the optic nerve, which is a common and important sign in glaucoma.

Eight percent of the cases presented an absent photomotor reflex. The lens is usually better examined after dilation. The study of the transparency of the lens is essential in the decision of a combined surgery. The presence of phacodonesis, pseudo capsular exfoliation, and dislocation should be noted for the differential diagnosis of POAG.

Associated cataract (22.2\%) was noted in this study, which is comparable of that of Z. Fadou [15] who found $25 \%$ of an associated cataract.

Eye pressure values in our patients ranged from $13 \mathrm{mmHg}$ to $50 \mathrm{mmHg}$, with an average of $27.34 \mathrm{mmHg} \pm 5.86$. 
The average ocular hypertension observed in the study of S. Chabi [5] is 28.13 $\mathrm{mmHg} \pm$ 6.06; Balo [19] reports ocular hypertension between $20 \mathrm{mmHg}$ and 29 $\mathrm{mmHg}$ in a study on the intraocular pressure of the Togolese population. Bernadin [2] found in Madagascar values of intraocular pressure oscillating between 21 and $28 \mathrm{mmHg}$. The average ocular hypertension in Sommer's study in Baltimore is $24.15 \pm 5.23 \mathrm{mmHg}$.

In our study, the iridocorneal angle (ICA) was open 360 degrees in the absence of any sign suggestive of secondary glaucoma (neovessels, exfoliation material, etc.) confirming the diagnosis of POAG.

In our study, eyes with a cup/disc ratio between 0.3 and 0.7 predominated with 59.5\%; 40\% had a cup/disc between 0.8 - 1, while Z. Fadou [15] reported that $12.2 \%$ had a cup/disc at 1 .

The average pachymetry in our patients was 522.16 microns \pm 41.45 , which is comparable to that of A. Fanny et al. [10] and Bron et al. [4].

In our study $55 \%$ of our patients had a thickness $<530$ microns which is comparable to the series of A. Fanny et al. [10] which reports $57.6 \%$ of thin corneas $<527$ microns.

The visual fields produced showed glaucomatous alterations in $96.5 \%$, which is coherent to the series of Tchabi (2011) [5] who found $99.2 \%$ of cases glaucomatous campimetric lesions.

In our study, $31.75 \%$ of the lesions were beginning, that is to say revealing a general decrease in sensitivity; $38 \%$ of the lesions were moderate with scanty beginners' scotomas and $22.75 \%$ of the lesions were severe showing scotomas extended to at least 02 dials. The visual field changes mainly concerned the scotoma of Bjerrum and the nasal projection. In this study, monotherapy was the most used treatment regimen, $60.4 \%$ of cases at the first consultation, which is consistent with the BRON series (58.2\%) [4].

In first therapeutic stage, treatment is generally initiated with a simple mono therapy with eye drops, unless the initial IOP is very high; in this case, two or more treatments can be indicated up to a quadritherapy which is the maximum treatment. Prostaglandin analogs with a single daily instillation are the most effective agents for reducing IOP and have the best tolerated systemic side effects.

Surgical treatment is generally undertaken as a second line when medical treatment is not tolerated, ineffective or improperly used by the patient or because of the cost of treatment, and glaucoma remains insufficiently controlled with either documented progression of the lesions or high risk of new lesions. The results of the Collaborative Initial Glaucoma Treatment Study (CIGTS) [20] confirm that first-line surgical treatment allows better control of IOP than does first-line medical treatment.

However, these results do not translate into better stabilization of the visual field, since patients who have had first-line surgical treatment have a higher risk of long-term cataracts [20]. In our study $11.34 \%$ benefited from a trabeculectomy with a success rate of $69.8 \%$. This rate is comparable to that of $Z$. Fadou [15] 
who found a success rate of $78.5 \%$. No complications were noted in our study. Compliance is a complex, multifaceted variable in the treatment of any disease that requires self-medication. Its evaluation by direct and indirect methods is difficult and the values depend on the criteria used [1]. According to Delfraisy [21], adherence to medical treatment is defined as behavior according to which the patient takes his medication with regularity and optimality, according to the conditions prescribed and explained by the doctor. For Fogarty et al. [22], compliance is defined as the ability of a person to take treatment according to a given prescription. The direct costs of treating primary open-angle glaucoma are correlated with the severity of the pathology and the number of treatments required.

The costs are lowest when the initial treatment of the patient is maintained as long as possible.

In Mauritania, the monthly cost of monotherapy is equivalent to $5 \$$, which increase to $20 \$$ in case of dual therapy.

In our study $60 \%$ of patients knew about the chronic nature of POAG, $57 \%$ knew that, in the absence of treatment, POAG progressed to irreversible blindness; $47.5 \%$ respected the regularity of the schedules for taking treatment. According to Vincent [23], the compliance rate varied from $52 \%$ to $73 \%$. These different variations are linked, on the one hand to the sample size, and on the other hand to the criteria studied. The overall compliance rate found in our study is close to that noted by Vincent [23]. When considering the regularity of treatment, Wane in Dakar [24] found 64.5\%. Most patients with POAG will have useful vision for their entire lives [3] [15] [25]. According to Hattenhauer et al., the incidence of blindness is estimated at $27 \%$ for unilateral blindness, and $9 \%$ for bilateral blindness, 20 years after the initial diagnosis [26]. According to Quigley and Vitale, the prevalence of bilateral blindness related to POAG is estimated at $8 \%$ in blacks and $4 \%$ in whites [27]. Treatments that lower IOP (medical, laser, and surgical) have shown that they can slow and stop the progression of the disease. In Early Manifest Glaucoma Trial (EMGT), 25\% drop in IOP reduced the progression of POAG from $45 \%$ to $62 \%$ after 6 years of follow-up. CIGTS [19] showed a relatively equivalent evolution after 5 years, whether the initial treatment was medical or surgical, with a significant evolution in only 10 to $13 \%$ of the study participants.

In the Advanced Glaucoma Intervention Study (AGIS) [28], the group of patients with an IOP always below $18 \mathrm{mmHg}$ did not develop additional loss of visual field; patients with an average IOP of $14 \mathrm{mmHg}$ or less during the first 18 months were better than those with an average IOP of $17.5 \mathrm{mmHg}$ or more.

In our study $7.9 \%$ of our patients had a negative light perception, $40 \%$ had a cup/disc of 0.8 to $1 ; 11.34 \%$ underwent a trabeculectomy with a success rate of $69.8 \%$. The delay in diagnosis found in our study should encourage us to raise awareness among the population over 40 years of age. In our study we noticed that the diagnosis was late in a large proportion of glaucomatous subjects which 
attests to the state of our health system which is more curative than preventive. Public authorities and health professionals as well as patient associations have a lot to do in this area.

In our series $50 \%$ of patients knew the chronic nature of POAG, $31 \%$ respected the regularity of the schedules for taking treatment which is lower than that founded by Wane in Dakar 64.5\% (24).

\section{Conclusion}

Primary open angle glaucoma (POAG) is a chronic optic neuropathy, long asymptomatic, requiring treatment for life. The World Health Organization estimated that 4.5 million people were affected by POAG blindness in 2008 worldwide; which represents more than $12 \%$ of the world blindness rate. The major risk of POAG is blindness, hence the importance of systematic screening, especially from the age of 40 . The visual field remains the key examination in POAG, papillary and macular ocular coherence tomography (OCT) confirm the diagnosis and allow long-term monitoring. The goal of treatment is to decrease the intraocular pressure to reach a target pressure. When medical treatment becomes insufficient, physical and/or surgical treatment is used; trabeculectomy remains the gold standard.

\section{The Limits of the Study}

- The study period is very short so the number of patients recruited is low.

- Lost patients are a real problem for follow-up.

- Lack of knowledge of the disease and lack of awareness mean that patients consult at a very late stage.

\section{Contributions Des Authors}

Doctor Mohamed Jiddou Sidi baba: Principal author. Doctor Ahmedou Moulaye Driss: co-author/recherche bibliographic. Doctor TFEIL Yahya: co-author/recherche bibliographic. Docteur Ahmed Taleb Batty: co-auteur/analyze statistics. Professor SidiSidiCheikh: co-author head of ophthalmology department.

All authors declare that they have read and approved the final version of the manuscript.

\section{Conflicts of Interest}

The authors declare no conflicts of interest regarding the publication of this paper.

\section{References}

[1] Bechetoille, A. (1987) Les clés d'un traitement médical réussi. In: Glaucomes, Jappenard, 301-304.

[2] Bernadin, P., Rabenantoandro, C. and Auzemery, A. (1994) La trabéculectomie à Madagascar: Etude rétrospective sur trois ans. Rev Int Trach, 125-135. 
[3] Oliver, J.E., Hattenhauer, M.G., Herman, D., et al. (2002) Blindness and Glaucoma: A Comparison of Patients Progressing to Blindness from Glaucoma with Patients Maintaining Vision. American Journal of Ophthalmology, 133, 764-772. https://doi.org/10.1016/S0002-9394(02)01403-4

[4] Bron, A., Nordmann, J.P., Rouland, J.F., Baudouin, C. and Sartral, M. (2006) Observational Survey on the Use of Dual Therapy in Ocular Hypertension or Glaucoma Treatment. Journal Français D’ Ophtalmologie, 29, 164-168.

[5] Tchabi, S., Abouki, C., Sounouvou, I., Yèhouessi, L., Doutetien, C. and Bassabi, S.K. (2011) Survey of Medical Treatment in Primary Open-Angle Glaucoma. Journal Français d Ophtalmologie, 34, 624-628. https://doi.org/10.1016/j.jfo.2011.07.009

[6] Coulibaly, A.N. (2002) Prévalence du GPAO dans le district de Bamakothèse. Fmpos Mali.

[7] CETS (1995) Rapport n 29. Le depistage du glaucome primitif a angle ouvert Montréal. $94 \mathrm{p}$.

[8] Organisation mondiale de la santé (2008) Les maladies oculaires prioritaires 2008. Genève, $10 \mathrm{p}$.

[9] Quigley, H.A. (1996) Number of People with Glaucoma Worldwide. British Journal of Ophthalmology, 80, 389-393. https://doi.org/10.1136/bjo.80.5.389

[10] Fanny, A., Ouattara, A., Coulibaly, F., Nigué, L., Gbé, K., et al. (2008) Épaisseur cornéenne centrale et erreur potentielle de la tonométrie à aplanation de Goldmann chez le patient noir africain atteint de glaucome primitif à angle ouvert: À propos de 340 yeux. Journal Français D' Ophtalmologie, 31, 405-408. https://doi.org/10.1016/S0181-5512(08)71435-9

[11] Chakib, A., Ouarrach, N., Haloui, M., Elbelhadji, M. and Amraoui, A. (2010) Viscocanalostomy: Preliminary Clinical Results. Journal Francais d Ophtalmologie, 33, 403-407.

[12] Javitt, J.C., McBean, A.M. and Nicolson, G.A. (1991) Under-Treatment of Glaucoma among Black Americans. The New England Journal of Medicine, 325, 1418-1422. https://doi.org/10.1056/NEJM199111143252005

[13] Wilson, M.R. and Martone, J.F. (1996) Epidemiology of Chronic Open Angle Glaucoma. In: Ritch, R., Shields, M.B. and Krupin, T., Eds., The Glaucomas, 2end Edition, Mosby, St Louis, 753-758.

[14] Hal Strauss, R.A., et al. (2010) American Academy of Ophthalmology, 11, 28.

[15] Fadou, Z. (2012) Aspect épidémiologie du GPAO en 2012. Thèse généraliste marocain.

[16] Rivera, C., Cantor, E., Castillo, A., Martinez, A., et al. (2020) Prevalence of Primary Open Angle Glaucoma among Patients with Diagnosis of Systemic Hypertension and Diabetes Mellitus: The Colombian Glaucoma Study. Open Journal of Ophthalmology, 10, 99-114. https://doi.org/10.4236/ojoph.2020.102012

[17] Laplace, O., Bron, A. and Nordmann, J.-P. (2006) Management of Ocular Hypertension and Chronic Open-Angle Glaucoma by French Ophthalmologists: The Role of Target Intraocular Pressure. Journal Français D' Ophtalmologie, 29, 353-358. https://doi.org/10.1016/S0181-5512(06)77693-8

[18] Sounouvou, I., Tchabi, S., Monteiro, S., Yehouessi, L., Doutetien, C. and Bassabi, S.K. (2012) Therapeutics of Primary Open-Angle Glaucoma in Cotonou: A Series of 224 Cases. Journal Français d Ophtalmologie, 35, 100-105. https://doi.org/10.1016/j.jfo.2011.02.015

[19] Balo, K.P., Anika, A., Banla, M., Agla, K., Djagnikpo, P.A. and Koffi-Gue, K.B. 
(2004) Distribution de l'excavation papillaire dans une population générale de 685 personnes âgées de plus de 40 ans et habitant le Sud Togo. Journal Français d Ophtalmologie, 27, 250-255. https://doi.org/10.1016/S0181-5512(04)96126-8

[20] Musch, D.C., Gillespie, B.W., Niziol, L.M., et al. (2006) Cataract Extraction in the Collaborative Initial Glaucoma Treatment Study (CIGTS): Incidence, Risk Factors, and the Effect of Cataract Progression and Extraction on Clinical and Quality of Life Outcomes. Archives of Ophthalmology, 124, 1694-1700.

https://doi.org/10.1001/archopht.124.12.1694

[21] Delfraisy, J.F. (2002) Prise en charge des personnes infectées par le VIH. In: Recommandations du groupe d experts, Flammarion, Paris, 35-39.

[22] Fogarty, L., Roter, D., Larson, S., Burke, J., Gillepsie, J. and Levy, R. (2002) Patient Adherence to HIV Medication Regimens: A View of Published and Abstract Reports. Patient Education and Counseling, 46, 93-108.

https://doi.org/10.1016/S0738-3991(01)00219-1

[23] Vincent, P.A. (1972) Patient's Viewpoint of Glaucoma Therapy. Sight Sav Rev, 42, 213-222.

[24] Wane, A.M., Ndiaye, M.R., Wade, A., Ndiaye, P.A., Ba, E.A., de Meideros, M., et al. (2003) L'observance au traitement médical dans le glaucome primitif à angle ouvert. Journal Français d Ophtalmologie, 26, 1039-1044.

[25] Renard, P.J. (2000) Les bonnes pratiques du GPAO. Journal Français d Ophtalmologie, 23, 278-284.

[26] Hatterhauer, M.G., Johnson, D.H., Ing, H.H., et al. (1998) The Probability of Blindness from Open-Angle Glaucoma. Ophthalmology, 105, 2099-2104. https://doi.org/10.1016/S0161-6420(98)91133-2

[27] Quigley, H.A. and Vitae, S. (1997) Models of Open-Angle Glaucoma Prevalence and Incidence in the United States. Investigative Ophthalmology \& Visual Science, 38, 83-91.

[28] (2000) The Advanced Glaucoma Intervention Study (AGIS): 7. The Relationship between Control of Intraocular Pressure and Visual Field Deterioration. The AGIS Investigators. American Journal of Ophthalmology, 130, 429-440. https://doi.org/10.1016/S0002-9394(00)00538-9 